\title{
Transdermal Lidocaine for Perioperative Pain: a Systematic Review of the Literature
}

\author{
Alexa Cohen \\ Thomas Jefferson University, alexa.cohen@jefferson.edu \\ Jordan Smoker \\ Thomas Jefferson University, jordan.smoker@jefferson.edu \\ Mohammad R. Rasouli \\ Thomas Jefferson University, mohammad.rasouli@jefferson.edu \\ Eric S. Schwenk \\ Thomas Jefferson University, eric.schwenk@jefferson.edu \\ Follow this and additional works at: https://jdc.jefferson.edu/si_ctr_2022_phase1 \\ Part of the Anesthesiology Commons, and the Translational Medical Research Commons \\ Let us know how access to this document benefits you
}

\section{Recommended Citation}

Cohen, Alexa; Smoker, Jordan; Rasouli, Mohammad R.; and Schwenk, Eric S., "Transdermal Lidocaine for Perioperative Pain: a Systematic Review of the Literature" (2020). Phase 1. Paper 85.

https://jdc.jefferson.edu/si_ctr_2022_phase1/85

This Article is brought to you for free and open access by the Jefferson Digital Commons. The Jefferson Digital Commons is a service of Thomas Jefferson University's Center for Teaching and Learning (CTL). The Commons is a showcase for Jefferson books and journals, peer-reviewed scholarly publications, unique historical collections from the University archives, and teaching tools. The Jefferson Digital Commons allows researchers and interested readers anywhere in the world to learn about and keep up to date with Jefferson scholarship. This article has been accepted for inclusion in Phase 1 by an authorized administrator of the Jefferson Digital Commons. For more information, please contact: JeffersonDigitalCommons@jefferson.edu. 


\title{
Transdermal Lidocaine for Perioperative Pain: a Systematic Review of the Literature
}

\author{
Alexa Cohen, Jordan Smoker, Mohammad R. Rasouli, Eric S. Schwenk*
}

Introduction: Recent data have shown that the risk of taking chronic opioids after surgery increases after about 5 days of postoperative opioid therapy. Alternatives to opioids are desirable, and transdermal lidocaine is one such perioperative multimodal agent. This review provides a summary of the perioperative studies that have examined transdermal lidocaine as an analgesic in the perioperative period.

Methods: We conducted searches of PubMed and Scopus databases. Studies involving patients who were undergoing surgery and were given either transdermal lidocaine, placebo, or active comparator in the perioperative period with the primary endpoint of improvement in pain were included in the analysis. Only randomized controlled trails were included.

Results: Overall, five out of the seven studies reported lower pain ratings in the lidocaine group compared to placebo. Three out of the four studies that used the mean visual analog scale (VAS) as primary endpoint reported that transdermal lidocaine decreased postoperative pain ratings at rest, which remained reduced for $6 \mathrm{~h}, 24$, and $72 \mathrm{~h}$. In four studies, there was no difference in opioid consumption between treatment and placebo groups. 
Discussion: This review demonstrates that transdermal lidocaine may provide a modest improvement in pain ratings in the perioperative period, but the number of studies was limited and the duration of benefit is limited. Although five out of seven studies showed a decrease in pain ratings with transdermal lidocaine, this reduction was typically only observed at rest and often did not translate to decreased opioid consumption, making the overall clinical benefit questionable. 